\title{
A fertile male with cystic fibrosis: molecular genetic analysis
}

\author{
C Barreto, L Marques Pinto, A Duarte, J Lavinha, M Ramsay
}

\begin{abstract}
A family study is presented in which the father of a girl with severe cystic fibrosis (CF) was also found to have CF but was mildly affected. He was diagnosed with three positive sweat tests including one after suppression with fludrocortisone. Genetic analysis showed that he is a compound heterozygote with the $\triangle F 508 \mathrm{CF}$ mutation associated with haplotype $B$ and a second $C F$ mutation associated with haplotype C. In this unusual, fertile CF male, the late age of diagnosis ( 30 years) and the mild clinical picture suggest that the compound genotype ( $\Delta$ F508/other $C F$ mutation) determines a much less severe form of the disease which might have gone unnoticed in the absence of a severely affected child. The implications of these findings for genetic counselling of families with CF are discussed.
\end{abstract}

It is widely accepted that, with a few exceptions, ${ }^{1-4}$ cystic fibrosis $(\mathrm{CF})$ males are infertile. This is thought to be largely because of a generalised increase in viscosity of the body fluids (including sperm) resulting from impaired regulation of chloride excretion/ resorption. ${ }^{56}$ As the life expectancy of CF patients is increasing with the application of suitable supportive measures, the fertility issue becomes more relevant. In this report the clinical and molecular genetic features of a fertile male with mild CF are described.

Serviço de Pediatria, Hospital de Santa Maria, Av Prof Egas Moniz, 1600 Lisboa, Portugal.

C Barreto, L Marques Pinto

Laboratório de Genética Humana, Instituto Nacional de Saúde, 1699 Lisboa Codex, Portugal.

A Duarte, J Lavinha

Department of Biochemistry and Molecular Genetics, St Mary's Hospital Medical School, London W2 1PG. M Ramsay*

Correspondence to Dr Lavinha.

${ }^{*}$ Present address: The South African Institute for Medical Research, Hospital Street, PO Box 1038, Johannesburg 2000, South Africa.

Received for publication 16 August 1990.

Revised version accepted for publication 29 October 1990.

\section{Case report}

The proband in this study is the father of a severely affected CF girl (figure). He had a history of sinopathy and mild gastrointestinal alterations without any noticeable effect on his nutritional status and quality of life. There was also reference to painful ejaculation and very thick sperm. Repeated sweat testing (including fludrocortisone suppression ${ }^{7}$ on one occasion) allowed the diagnosis of $\mathrm{CF}$ to be made (figure).

The results of the family study with $\mathrm{CF}$ linked probes PT-3, XV2c, KM19, D9, G2, and $\mathrm{H}_{80}^{8} 9$ and oligonucleotide probes for normal and deleted codon 508 of the CFTR gene $(\Delta \mathrm{F} 508)^{10}$ are shown in the figure. The severely affected girl is homozygous for $\Delta$ F508 and haplotype B $(-1+$ for probes XV2c and $\mathrm{KM} 19$, respectively) and her mildly affected father carries the same mutation/haplotype association

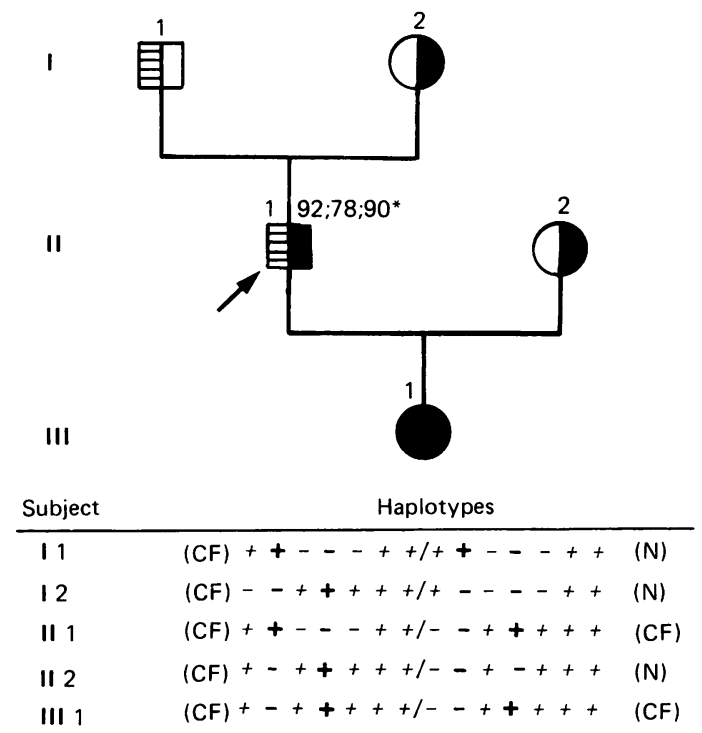

Pedigree of a cystic fibrosis family with a fertile affected male. Sweat test results ( $m E q / 1,{ }^{*}$ after suppression by fludrocortisone) are shown above the proband (II.1). Haplotypes, from left to right, are for probes $P T-3, X V 2 c, C S .7, K M 19, D 9, G 2$, and $H 8 O$, respectively. A black half symbol indicates the presence of the $\Delta F 508$ mutation while a hatched half symbol indicates the presence of an unknown $C F$ allele. 
on one chromosome and another CF mutation associated with haplotype $\mathrm{C}(+/-)$ on the other chromosome. The segregation of ApoCII (AC) $)_{n}$ alleles is consistent with II.1 being the father of III.1. The frequency of the haplotype $1--++\mathrm{CF} /(\mathrm{PT}-3$, XV2c, CS.7, KM19, cystic fibrosis mutation), which is present in both II.1 and III.1, is 0.0056 in the general Portuguese population, ${ }^{11}$ giving a $99 \cdot 44 \%$ probability of paternity.

\section{Discussion}

The case described above is apparently identical, as far as haplotypes are concerned, to that of an Iranian CF mother described recently. ${ }^{12}$ A molecular epidemiological survey of $\mathrm{CF}$ in the Portuguese population ${ }^{13}$ indicated that a sizeable proportion (22\%) of the CF chromosomes belong to haplotype C, while the typically northern European haplotype $B$ accounts for only $52 \%$ of CF chromosomes. Similar haplotype distributions have been found in other southern European populations. ${ }^{14}$ The fertile male with mild CF presented here is, therefore, a compound heterozygote with one severe and one mild CF mutation. However, another unrelated patient, homozygous for haplotype $\mathrm{C}$ and not carrying the $\Delta$ F508 mutation, showed a very severe clinical picture from birth and eventually died from acute pulmonary heart disease at the age of 7 years (personal observation). These findings suggest a heterogeneous molecular pathology associated with haplotype C chromosomes in the Portuguese population. Only the complete definition of the molecular basis of CF in these two patients (currently under way) will make it possible to establish a genotype/phenotype correlation.

This study raises several points. (1) The diagnosis of almost asymptomatic CF patients in adulthood dramatically changes their risk of bearing affected children. With a carrier partner, $50 \%$ of their children will be affected and with a non-carrier partner all offspring will be CF carriers. (2) If a clear genotype/ phenotype correlation is found, the prediction of the clinical course of the disease based on the genotype will enable at risk couples to make a more informed decision regarding their progeny. (3) If there is any indication that a parent of a CF child may have some complaint possibly related to $\mathrm{CF}$, a sweat test should be performed on that parent. (4) When general population screening becomes available, should persons identified as being carriers be investigated further in order to determine whether they may actually be compound heterozygotes for $\mathrm{CF}$ ?

This report raises the possibility that very mild CF cases may remain undiagnosed for life. It remains to be seen to what extent this is so.

This work was supported by a grant from JNICT (project 87187). MR was supported by the South African Institute for Medical Research and the South African Medical Research Council. We thank Professor R Williamson, St Mary's Hospital, London for having stimulated the reporting of this case.

1 Feigelson Y, Pecare Y, Schwachman H. A propos d'une paternité chez un malade atteint de mucoviscidose. Arch Fr Pediatr $1969 ; 26: 937-44$.

2 Levine SB, Stern RC. Sexual function in cystic fibrosis. Chest 1982;81:422-8.

3 Blank R, Mendoza EM. Fertility in a man with cystic fibrosis. f Am Med Assoc 1976;235:1364.

4 Taussig LM, Lobeck CC, Di Sant'Agnese PA, Ackerman DR, Kattwinkel J. Fertility in males with cystic fibrosis. $N \mathrm{Engl} \mathcal{f}$ Med 1972;287:586-9.

5 Denning CR, Sommers SC, Quigley HJ. Infertility in male patients with cystic fibrosis. Pediatrics 1968;41:7-17.

6 Quinton PM. Defective epithelial ion transport in cystic fibrosis. Clin Chem 1969;35:726-30.

7 Hodson ME, Beldon I, Power R, Duncan FR, Ramber M, Batten JC. Sweat tests to diagnose cystic fibrosis in adults. $B M \mathcal{J}$ 1983;286:1381-3.

8 Estivill X, Scambler PJ, Wainwright BJ, et al. Patterns of polymorphism and linkage disequilibrium for cystic fibrosis. Genomics 1987;1:257-63.

9 Estivill X, McLean C, Nunes V, et al. Isolation of a new DNA marker in linkage disequilibrium with cystic fibrosis, situated between J3.11 (D7S8) and IRP. Am F Hum Genet 1989;44: 704-10.

10 Kerem BS, Rommens JM, Buchanan JA, et al. Identification of the cystic fibrosis gene: genetic analysis. Science 1989;245: 1073-80.

11 Duarte A, Tavares MC, Marques-Pinto L, et al. Cystic fibrosis among the Portuguese: genetic heterogeneity or founder effect? foint Meeting of the Portuguese and Spanish Genetics Societies, Evora, 1989.

12 Feldman GL, Lewiston SD, Fernbach WE, et al. Prenatal diagnosis of cystic fibrosis by using linked DNA markers in 138 pregnancies at 1-in-4 risk. Am J Med Genet 1989;32:238-41.

13 Duarte A, Barreto C, Marques-Pinto L, et al. Cystic fibrosis in the Portuguese population: haplotype distribution and molecular pathology. Hum Genet 1990;85:404-5.

14 Estivill X, Gasparini P, Novelli G, et al. Linkage disequilibrium for DNA haplotypes near the cystic fibrosis locus in two South European populations. Hum Genet 1989;83:175-8. 